\title{
Ineffective chronic illness behaviour in a patient with long-term non-psychotic psychiatric illness
}

\author{
Bauke Koekkoek, ${ }^{1}$ Willem van Tilburg² \\ ${ }^{1}$ Institute for Professionalization, Gelderse Roos Mental Health Care, Wolfheze, The Netherlands \\ ${ }^{2}$ Outpatient Care, GGZ InGeest, Amsterdam, The Netherlands
}

Correspondence to Bauke Koekkoek, b.koekkoek@propersona.nl

\begin{abstract}
Summary
This case report offers a different perspective on a patient with a long-term non-psychotic psychiatric disorder that was difficult to specify. The patient, a man in his 50s, was unable to profit from outpatient treatment and became increasingly dependent on mental healthcare - which could not be understood based on his history and psychiatric symptoms alone. By separating symptoms from illness behaviour, the negative course of this patient's treatment is analysed. Focusing on ineffective chronic illness behaviour by the patient, and mutual ineffective treatment behaviour by the clinicians, it becomes clear that basic requirements of effective treatment were unmet. By making a proper diagnosis, clarifying expectations and offering a suitable therapy, ineffective illness behaviour was diminished and this 'difficult' case became much easier for both patient and clinicians. The illness behaviour framework offers a useful, systematic tool to analyse difficulties between patients and clinicians beyond psychiatric symptoms or explanations.
\end{abstract}

\section{BACKGROUND}

This case report offers a new perspective on a patient with a long-term non-psychotic psychiatric disorder that was difficult to specify, due to its features of both an anxiety disorder, a depressive disorder, a substance use disorder and a personality disorder. Non-psychotic psychiatric disorders are highly frequent in the general population: lifetime prevalence in the USA is $28.8 \%$ for anxiety disorders, $20.8 \%$ for depressive disorders, $14.6 \%$ for substance use disorders ${ }^{1}$ and $9.1 \%$ for personality disorders. ${ }^{2}$ Comparable percentages were found in Britain, Australia and other Western countries. ${ }^{3}{ }^{4}$ Only a small proportion of these disorders is actually treated in specialist mental healthcare, ${ }^{3}$ mostly on an outpatient basis. Not all treated patients reach symptomatic or functional recovery as expected and chronicity may occur. In depression, for instance, chronicity is estimated at $20 \% .^{5}$ Public psychiatric services tend to care for the more long-term patients that often are high users of (mental) health services, ${ }^{6-9}$ especially those with several non-psychotic disorders. ${ }^{4}$

Interactions between these long-term patients and clinicians may be problematic since the latter sometimes doubt the legitimacy of their prolonged sick-role claim. ${ }^{10}$ Patients may be considered in search of secondary gain, ${ }^{11}$ or wilfully obstructing psychiatric treatment, ${ }^{12}$ resulting in denial of appropriate care by professionals. However, the reverse may also be true: a lack of appropriate care or treatment may lead to non-recovery and long-term attendance. An analysis of this problem should take into account not only symptoms, but also reasons for prolonged service use. Symptoms and service use may be separated using the concept of illness behaviour, introduced by Mechanic and Volkart. ${ }^{13}$ This term refers not only to the different ways in which people perceive, evaluate and respond to symptoms, but also to the ways in which they seek help and to their behaviour in healthcare systems. Research into illness behaviour in patients with physical diseases has shown that patients who claim help more actively, are treated more aggressively but less effectively. ${ }^{14-16}$ In this case report we use the illness behaviour framework to analyse the longterm attendance and perseverance of symptoms in a patient with a non-psychotic disorder that was difficult to specify.

\section{CASE PRESENTATION}

$\mathrm{C}$ is a man in his 50 s. His mother has always been focused on (academic) achievements, his father has never paid much attention to him. Contact with his younger brother ( -2 years) has always been good. During early adolescence, his father left the family to live with another woman. C has not been willing to have any contact with his father since. From an early age, he has been bullied because of a clearly visible handicap - from birth he has had one normal hand and one hand with two missing and three much shorter fingers. Despite the obvious handicap, he has managed to live quite well with this condition. During secondary school he was forced to have oral sex with two older boys, which has traumatised him severely. C has been married for several years and has two children, who now are adults. His wife suddenly left him 17 years ago, for another man as turned out later. Contact with his children is difficult and has been completely absent during some periods. C lives alone in a two-room apartment in a small city, paid for by a disability pension he receives since 5 years because of psychiatric illness. Before, he held a responsible and well-paid job as an air-traffic controller in a major international airport for many years. Multiple severe debts, however, have been accumulating over the past years, of which the exact scale and origins are unknown.

His brother passed away some 7 years ago, after which C started to suffer from anxiety and panic attacks, depression 
and dissociations. He reported flashbacks about the sexual assault in adolescence and attempted suicide with medication a few times, for which he was in day treatment for 6 months. This treatment was terminated after he was found to be using alcohol repeatedly. Before his brother's death, some contacts with mental healthcare already had taken place: 10 years earlier $\mathrm{C}$ attempted suicide (after the divorce) and was hospitalised for some months. Some years later, a few short admissions took place, again after attempted suicide and for detoxification from substances. Also, he followed psychotherapy for the panic and anxiety symptoms. Course and results of these respective treatments are very unclear, since written records are unavailable from the primary care physician, or the patient himself.

\section{INVESTIGATIONS}

Six years ago $C$ was referred to our community mental health centre by the aforementioned day treatment centre for 'aftercare'. He had been admitted to this day treatment after referral by regional crisis services following a failed suicide attempt. The previous loss of his brother was believed to be the provoking factor of this crisis. Psychological tests suggested an IQ above average and intact cognitive functioning. The diagnostic process progressed slowly and arduously: the intakers could not have an interview with C's significant others due to various failed appointments. Some doubts existed about the truth of his statements. For instance, he claimed to have been hospitalised because of urgent physical problems but his primary care physician could not confirm this. This physician also had never spoken to a family member. Despite these questions, that could not be answered even after extensive multidisciplinary consultation, $\mathrm{C}$ was assigned to a community psychiatric nurse (CPN) for supportive treatment and a psychiatric resident for psychopharmacological treatment.

\section{DIFFERENTIAL DIAGNOSIS}

No definite or main diagnosis was made, despite substantial efforts to do so. On Axis I the following diagnoses were being considered: adjustment disorder with mixed anxiety and depressed mood, generalised anxiety disorder, posttraumatic stress disorder, depressive disorder and substance dependency. A diagnosis on Axis II was deferred, but a personality disorder with avoidant and dependent traits was considered.

\section{TREATMENT}

A so-called supportive structuring treatment was started, focusing on 'discussing the problems in the here and now that the client wants to work on'. It must be stated that there was no clear rationale for the indication of this particular treatment, and that the indication may well have been the consequence of ignorance about what to do, since there was no clear diagnosis. Also, the patient repeatedly stressed his urgent need for treatment, a kind of illness behaviour that may evoke a strong sense in the treating professionals that this patient was in great need of whichever form of treatment. Rapport between $\mathrm{C}$ and his treating professionals was established soon and developed into a positive therapeutic alliance. The treatment consisted of symptom management through medication and talking sessions, at times complemented with partial day treatment (eg, social skills training).

Symptoms, however, did not disappear and treatment was complicated by repeated dissociation and amnesia for intrusive events, among which self-mutilation. Despite the limited success, $\mathrm{C}$ was very content with his clinicians and hardly ever complained about a lack of progress. He fiercely criticised, however, other professionals that he came in contact with after office hours, during crisis calls. Although efforts were made to fully inform these professionals, they for instance had immediate access to a three-page crisis plan and also access to the full paper file, these were quite unsuccessful. Repeatedly, he requested an increase of the amount of care, especially permission to call after hours or to receive home-based psychiatric care. The frequency of the outpatient sessions was variable, though never more often than once every 2 weeks. When the treating CPN left for another department, treatment was continued by a new CPN (who again offered supportive treatment) and a new psychiatrist (who again offered psychopharmacological treatment).

A few weeks into this transition, $C$ stated he had been mugged near his house, which made him very anxious. The new CPN offered a higher contact frequency to help him through this difficult period. Yet, this episode lasted for a long time and $\mathrm{C}$ kept on needing the additional care. Due to this crisis-like start, the new CPN did not make a treatment plan, and clear arrangements on the contact frequency and mutual responsibilities were complicated by C's ongoing claim for help. He had the habit to call the CPN directly and to start talking right away, even if the CPN was in the middle of another conversation. Even though the crisis appeared to remit at a certain moment, no discussion about the nature and the goal of this treatment took place. Treatment continued, sometimes with crises and in-between periods of relative rest, the latter especially when $C$ had an affair with a woman.

Repeatedly, others gave alarming messages about his behaviour. For instance, the police contacted the CPN to inquire about his assessment of the truth value of the aforementioned mugging. The CPN was contacted twice by other (female) clients because $\mathrm{C}$ had behaved inappropriately and claiming towards them, after an initial cheerful contact in skills training sessions. Out of hours, C repeatedly contacted crisis services. During these encounters it was very difficult for professionals to make contact with him and most often he predicted suicide attempts or selfmutilation without accepting help offered.

When the CPN needed to transfer the patient to a colleague, due to an internal reorganisation, a new crisis occurred. C, already instable because of a physical disease, felt rejected and unseen and made an increasing number of suicidal gestures. Meanwhile, the CPN was unsuccessful in finding a new professional. Despite provision of full information on the patient, and repeated personal contact of the referring CPN with the other departments, the latter claimed that $\mathrm{C}$ would be unsuitable for their treatment programs. C became increasingly emotional and relapsed into anxiety more and more. He claimed to be unable to come to the centre and threatened to call the press because of negligence of the mental healthcare facility. The treating CPN 
then decided, notwithstanding a certain amount of annoyance and despair but also out of compassion, to continue treatment himself yet in a different way.

\section{OUTCOME AND FOLLOW-UP}

The CPN discussed the problematic contact between $\mathrm{C}$ and health services, from the view that he was consistently running the risk to be perceived as a 'difficult' patient. Because of his chaotic help-seeking style, his difficulties in accepting help and his lack of improvement, professionals might consider him a difficult case. Furthermore, the CPN offered a tentative explanation for C's difficulties with health providers, originating in various life experiences that led him to believe that he was never seen as a real and valuable human being. Also, some arrangements were made about the CPN's availability, the focus of treatment and long-term goals. This discussion not only helped $\mathrm{C}$ to improve his relation with both the CPN and the treating psychiatrist, but also enabled these clinicians to see that the content of treatment deserved more attention.

Following this awareness, the treating psychiatrist hypothesised a diagnosis (complex post-traumatic stress disorder; CPTSD) and suggested a specific treatment for it, which the patient was able to start after a long and difficult intake procedure. Although such a treatment had been pursued earlier, that referral failed due to the patient's increase of stress. This time, however, both referral and treatment succeeded. C felt that he was finally treated for the problems he had had for a long time, resulting in less complaints and lower use of (mental) health services. The differences between the first and the second referral initially seemed small, but proved to be essential and warrant further attention. The first time, there was no diagnosis, only the suggestion - made by a crisis intervention worker - that $C$ was traumatised and might profit from an individual psychotherapy. The second time, the various symptoms and complaints were accounted for by a diagnosis that proved to be highly recognisable for C. Additionally, he felt understood and validated by this diagnosis, and was reassured by the careful approach inherent to the treatment model, which was outlined by the psychiatrist. Unlike the former, this suggested trauma treatment appeared to be well-thought out and adjusted to the patient. Also, the referral took place in a structured treatment atmosphere in which this treatment was seen as a chance, not as a last resort or - worse a means to refer a 'difficult' patient elsewhere.

\section{PATIENT'S VIEW}

Since mutual agreement between clinicians and patient proved to be essential in this case, we invited the patient to read the full report and comment on it. We have transcribed his response into the following narrative.

Two responses come to my mind, reading this case description. First, I feel embarrassed that I was so 'difficult' for professionals. Indeed I did some things that are difficult to understand or tolerate. Second, however, I also feel disappointment and frustration about the interpretation of my behaviours as 'difficult' by professionals. I never intentionally obstructed treatment, I just felt very desperate and helpless. Meanwhile, I have more and better coping strategies than before, in part thanks to my CPTSD therapy. I am glad that my primary care giver, the CPN described in this paper, stayed with me during difficult times and that we finally managed to find and start a proper therapy for my condition. In my view, psychiatric professionals should always do their utmost best to understand the sometimes difficult behaviours of their patients, even if this is a lot to ask at time. Patients do not ask for fancy words or authoritarian commands ('you should do this and do that'), but just want a human person-to-person contact.

\section{DISCUSSION}

Some observations can be made from this case. First, treatment was started with a broad goal but without either a clear diagnosis, an explanatory hypothesis or a preset method. Second, there was a positive working alliance with the key clinician but this did not result in positive outcomes. Third, treatment was continued despite the obvious lack of structure and success. It appears that the key-clinician had become the most important person in the care, and possibly even the life, of this patient. Patient and provider had become entangled in what may be termed a collusion.

To understand this entanglement we use the concept of illness behaviour. The combination of severe psychiatric symptoms, many social problems and especially chaotic help-seeking behaviour (eg, missed appointments, out-ofhours crisis and in-between appointments phone calls) makes it difficult for professionals to structure treatment. The lack of a proper diagnosis marks the start of a haphazard treatment process in which the lack of substance (diagnosis, goals, methods) is compensated by form (the working alliance). The combination of a clinician change and the adverse event of the robbery, makes the new key clinician offer extra care that, however, turns out to be very hard to decrease. The patient appears to have become used to the availability of the clinician and uses him as an important source of social contact (considering that the patient has few significant others).

Meanwhile, the clinician himself becomes used to a patient that requires constant attention and evokes considerable worry (eg, because of suicidal gestures). He may start to believe that the patient is unable to tolerate a less supportive contact and a more therapeutic exploration of behaviours, resulting in a treatment that does nothing more than 'helping' the patient through adverse situations. As long as the professional is able to offer this support, and the psychiatric service allows him to do so, there are relatively few problems. However, once the professional starts to have negative problematic encounters on behalf of the patient (eg, because professionals raise doubts about the patient's claim to illness) or becomes tired to attend to the patient so intensively, problems arise.

At this point, frustration and demoralisation may tempt the professional to attribute the patient's behaviour to purposive claiming of time and energy, deliberate obstruction of treatment, or a bad character in general. The patient then is at risk of exemption from mental healthcare because he is considered not really ill but seeking something else (eg, relief from work duties, or an ever-attentive person around). Referral may be the strategy of choice for clinicians that attribute this long-term attendance to 'badness'. A second strategy may be to limit treatment to the least necessary to prevent exacerbation of symptoms and psychiatric crises, referred to by experts as 'pampering and dithering'. ${ }^{17}$ The 
patient may respond to such a threat of losing an important figure with an increase of symptoms and demand upon the key clinician - thus only 'proving' that the clinician is right in assuming that the patient just wants attention.

We may describe the patient's behaviour as a form of ineffective chronic illness behaviour that has been jointly but inadvertently created by patient and professional. ${ }^{16} 18$ Analysing the situation from this perspective, another strategy - apart from referral or 'pampering and dithering' - is within reach: making a fresh start in the treatment process of the so-called 'difficult' patient. Such an endeavour includes, but is not necessarily limited to: a disentanglement of symptoms and (learned) illness behaviour, an analysis of the dynamics of the treatment alliance, a reconsideration of the given diagnosis and available treatment options, and preferably - a discussion with the patient about aforementioned issues. In this case, we choose to discuss the issues openly with the patient, starting from the concept of the 'difficult' patient, who runs the risk to be expelled from every healthcare system available. We then jointly established a explanatory theory of patient's claim on care: an enduring lack of recognition of qualities and vulnerabilities by important others. We also jointly established that treatment had been reinforcing the behaviours following from this need, instead of exploring its antecedents. The consulting psychiatrist suggested a new diagnosis that explained many of the patient's symptoms (CPTSD ${ }^{19} 20$ ) and proposed a treatment (consisting of both individual and group psychotherapy $^{21}$ ) for this disorder.

This treatment was surprisingly successful, despite its relative resemblance to earlier treatments. However, this was the very first time C's complex trauma was acknowledged by therapists and discussed within a group of peers, which may have been two very validating experiences. A psychotherapist prepared the patient for and provided the therapy, while the psychiatrist managed medication. The CPN assumed a case-manager role, coordinating efforts to ameliorate social problems (including work and meaningful contacts), to structure access to additional psychiatric care (eg, crisis intervention, hospitalisation) and to be a trusted person in the background. So far, these joint efforts have decreased the patient's symptoms, improved his social functioning and limited his healthcare use.

Practically, these collaborative efforts are increasingly being facilitated by an electronic patient file, to which clinicians from both acute and community care settings have access. This file contains a shared care plan that appears to be looked at more frequently than in the old paper file. It allows registration and consultation of all healthcare contacts by all involved professionals, which in this case prevents miscommunication and misunderstanding among professionals.

On a more theoretical level we may understand the patient's chronic illness behaviour as a function of his individual needs, the limited social system, clinician's pessimism and services' lack of structure with patients like these.

\section{Learning points}

- Difficulties in treatment interactions need analysis beyond the patient's presumed diagnosis or disorder.

- Especially when patients' behaviour during treatment is unusual or unexpected related to the primary symptoms, a serious analysis of patients' illness behaviour is warranted.

- The concept of illness behaviour offers an explanatory framework for patient's behaviours towards the primary clinician and in the healthcare system.

- Ineffective chronic illness behaviour may be induced in the patient by a treatment that lacks a clear starting point (preferably a diagnosis or current problems), a direction (goals) and a treatment frame (an explication of expectations and rules governing the therapeutic encounter).

- Once ineffective chronic illness behaviour is recognised, the primary clinician should structure treatment according to clear guidelines which may result in a restoration of hope and decrease of ineffective behaviours by both patient and professional.

- Once treatment is restructured, it is possible and important to keep up hope and an open eye for therapeutic options that previously seemed unsuitable.

Competing interests None.

Patient consent Obtained.

\section{REFERENCES}

1. Kessler RC, Chiu WT, Demler O, et al. Prevalence, severity, and comorbidity of 12-month DSM-IV disorders in the National Comorbidity Survey Replication. Arch Gen Psychiatry 2005;62:617-27.

2. Lenzenweger MF, Lane MC, Loranger AW, et al. DSM-IV personality disorders in the National Comorbidity Survey Replication. Biol Psychiatry 2007:62:553-64.

3. Kohn R, Saxena S, Levav l, et al. The treatment gap in mental health care. Bull World Health Organ 2004;82:858-66.

4. Andrews G, Henderson S, Hall W. Prevalence, comorbidity, disability and service utilisation. Overview of the Australian National Mental Health Survey. Br J Psychiatry 2001;178:145-53.

5. Spijker J, de Graaf R, Bijl RV, et al. Duration of major depressive episodes in the general population: results from The Netherlands Mental Health Survey and Incidence Study (NEMESIS). Br J Psychiatry 2002;181:208-13.

6. Dickey B, Azeni H. Persons with dual diagnoses of substance abuse and major mental illness: their excess costs of psychiatric care. Am J Public Health 1996:86:973-7.

7. French MT, McGeary KA, Chitwood DD, et al. Chronic illicit drug use, health services utilization and the cost of medical care. Soc Sci Med 2000;50:1703-13.

8. Kent S, Fogarty M, Yellowlees P. A review of studies of heavy users of psychiatric services. Psychiatr Serv 1995; 46:1247-53.

9. Bender DS, Dolan RT, Skodol AE, et al. Treatment utilization by patients with personality disorders. Am J Psychiatry 2001;158:295-302.

10. Koekkoek B, van Meijel B, Hutschemaekers G. "Difficult patients" in mental health care: a review. Psychiatr Serv 2006;57:795-802.

11. van Egmond J, Kummeling I. A blind spot for secondary gain affecting therapy outcomes. Eur Psychiatry 2002;17:46-54.

12. Bender DS. The therapeutic alliance in the treatment of personality disorders. J Psychiatr Pract 2005;11:73-87. 
13. Mechanic D, Volkart EH. Stress, illness behavior, and the sick role. Am Sociol Rev 1961;26:51-8.

14. Waddell G, Bircher M, Finlayson D, et al. Symptoms and signs: physical disease or illness behaviour? Br Med J (Clin Res Ed) 1984;289:739-41.

15. Waddell G, Main CJ, Morris EW, et al. Chronic low-back pain, psychologic distress, and illness behavior. Spine 1984:9:209-13.

16. Wooley SC, Blackwell B, Winget C. A learning theory model of chronic illness behavior: theory, treatment, and research. Psychosom Med

1978:40:379-401.

17. Koekkoek B, van Meijel B, Schene A, et al. Clinical problems in the longterm care of patients with chronic depression. J Adv Nurs 2008;62:689-97.
18. Whitehead WE, Winget C, Fedoravicius AS, et al. Learned illness behavior in patients with irritable bowel syndrome and peptic ulcer. Dig Dis Sci 1982;27:202-8.

19. Herman JL. Complex PTSD: a syndrome in survivors of prolonged and repeated trauma. J Trauma Stress 1992;5:377-91.

20. Courtois CA. Complex trauma, complex reactions: assessment and treatment. Psychotherapy: Theory, Research, Practice, Training 2004; 41:412-25

21. Zlotnick C, Shea TM, Rosen K, et al. An affect-management group for women with posttraumatic stress disorder and histories of childhood sexual abuse. J Trauma Stress 1997;10:425-36.

This pdf has been created automatically from the final edited text and images.

Copyright 2010 BMJ Publishing Group. All rights reserved. For permission to reuse any of this content visit

http://group.bmj.com/group/rights-licensing/permissions.

BMJ Case Report Fellows may re-use this article for personal use and teaching without any further permission.

Please cite this article as follows (you will need to access the article online to obtain the date of publication).

Koekkoek B, Van Tilburg W. Ineffective chronic illness behaviour in a patient with long-term non-psychotic psychiatric illness: a case report. BMJ Case Reports 2010;10.1136/bcr.02.2010.2739, date of publication

Become a Fellow of BMJ Case Reports today and you can:

- Submit as many cases as you like

- Enjoy fast sympathetic peer review and rapid publication of accepted articles

- Access all the published articles

Re-use any of the published material for personal use and teaching without further permission

For information on Institutional Fellowships contact consortiasales@bmjgroup.com

Visit casereports.bmj.com for more articles like this and to become a Fellow 